\title{
DNA methylation reader MECP2: cell type- and differentiation stage-specific protein distribution
}

\author{
Congdi Song 1 , Yana Feodorova', Jacky Guy ${ }^{2}$, Leo Peichl ${ }^{3}$, Katharina Laurence Jost ${ }^{4}$, Hiroshi Kimura ${ }^{5}$, \\ Maria Cristina Cardoso ${ }^{4}$, Adrian Bird ${ }^{2}$, Heinrich Leonhardt ${ }^{1}$, Boris Joffe ${ }^{1 \wedge}$ and Irina Solovei ${ }^{i^{*}}$
}

\begin{abstract}
Background: Methyl-CpG binding protein 2 (MECP2) is a protein that specifically binds methylated DNA, thus regulating transcription and chromatin organization. Mutations in the gene have been identified as the principal cause of Rett syndrome, a severe neurological disorder. Although the role of MECP2 has been extensively studied in nervous tissues, still very little is known about its function and cell type specific distribution in other tissues.

Results: Using immunostaining on tissue cryosections, we characterized the distribution of MECP2 in 60 cell types of 16 mouse neuronal and non-neuronal tissues. We show that MECP2 is expressed at a very high level in all retinal neurons except rod photoreceptors. The onset of its expression during retina development coincides with massive synapse formation. In contrast to astroglia, retinal microglial cells lack MECP2, similar to microglia in the brain, cerebellum, and spinal cord. MECP2 is also present in almost all non-neural cell types, with the exception of intestinal epithelial cells, erythropoietic cells, and hair matrix keratinocytes. Our study demonstrates the role of MECP2 as a marker of the differentiated state in all studied cells other than oocytes and spermatogenic cells. MECP2-deficient

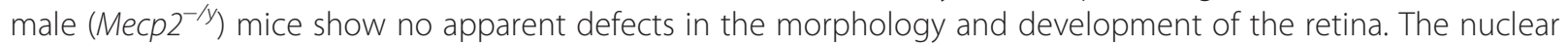
architecture of retinal neurons is also unaffected as the degree of chromocenter fusion and the distribution of major histone modifications do not differ between Mecp2 $2^{-1 y}$ and Mecp $2^{\text {wt }}$ mice. Surprisingly, the absence of MECP2 is not compensated by other methyl-CpG binding proteins. On the contrary, their mRNA levels were downregulated in Mecp2 $2^{-1 y}$ mice.

Conclusions: MECP2 is almost universally expressed in all studied cell types with few exceptions, including microglia. MECP2 deficiency does not change the nuclear architecture and epigenetic landscape of retinal cells despite the missing compensatory expression of other methyl-CpG binding proteins. Furthermore, retinal development and morphology are also preserved in Mecp2-null mice. Our study reveals the significance of MECP2 function in cell differentiation and sets the basis for future investigations in this direction.
\end{abstract}

Keywords: MECP2, MBD, Histone modifications, Nuclear architecture, Mouse retina, Retina development, Mouse tissues

\section{Background}

Methyl-CpG binding protein 2 (MECP2) was discovered as a protein that selectively binds methylated DNA [1]. Mutations of the MECP2 gene were later identified as the principal causative factor for Rett syndrome, a severe progressive neurological disorder affecting almost exclusively females [2]. Mild loss of function mutations,

\footnotetext{
* Correspondence: Irina.Solovei@|rz.uni-muenchen.de

'Deceased

'Department of Biology II, Center for Integrated Protein Science Munich (CIPSM), Ludwig Maximilians University Munich, Grosshadernerstrasse 2, 82152 Planegg-Martinsried, Germany

Full list of author information is available at the end of the article
}

duplications, and expression level alterations has also been found in patients with a plethora of neurological and mental phenotypes [3-6]. In mice, deletion of the Mecp 2 gene causes symptoms similar to those of Rett syndrome even when the deletion is restricted to the brain [7-10], while expression of Mecp2 rescues the Rett phenotype. More effective rescue was achieved through embryonic, compared to early postnatal expression [11-13], whereas targeted expression in postmitotic neurons resulted in asymptomatic mice [12,14]. Mecp2 mutant mice exhibit abnormalities in the number of synapses [15], the morphology of neuronal processes [16,17], neuronal maturation [16], and the neurophysiological activity of these cells 
$[18,19]$. These effects are associated with particular neuron types. For instance, brain stem GABA-ergic neurons are affected, but glycinergic ones are not [20]. Glutamatergic neurons of the brain and their synapses are also affected through the expression level of brain-derived neurotrophic factor (BDNF) [21] which is regulated by MECP2 in a neuronal activity-dependent manner $[17,22,23]$.

The results listed above conform to the conclusion that MECP2 deficiency leads to subtle changes in the expression levels of genes causing diverse and widespread phenotypic changes [24]. There is growing evidence that both Mecp2null astrocytes [25] and microglia [26] affect the dendritic morphology of neurons. Lack of MECP2 causes global histone H3 hyperacetylation in neurons [10,27], which can have different effects on transcription depending on which lysine residues are acetylated. It remains, however, unknown if global histone $\mathrm{H} 3$ acetylation levels increase exclusively in neurons or also take place in glia $[10,21,27]$. Factual data about the phenotypic changes in various tissues of Mecp2-null mice are currently insufficient and partially controversial.

In addition to its role in transcriptional regulation, MECP2 appears to be important for maintenance of the general chromatin organization. Mecp2-null brain shows a ca. 1.6-fold upregulation in spurious transcription of repetitive DNA, in particular L1 retrotransposons and pericentromeric satellites [27], which have been implicated in maintenance of the nuclear architecture and its formation during cell differentiation [28-30]. In all mouse cells, subcentromeric repetitive blocks, composed of major satellite repeat, form spherical bodies, so called chromocenters that are predominantly located at the nuclear periphery and adjacent to the nucleolus. Remarkably, mouse chromocenters are extremely enriched in MECP2 [1] and the same applies to clusters of human alphoid satellites, also often called chromocenters. There is growing evidence that DNA methylation and MECP2 binding to methylated DNA are pivotal for chromocenter formation and, therefore, the establishment of normal nuclear architecture [31-35]. MECP2 indeed seems to be required for chromocenter fusion during differentiation $[8,32,36]$, although other methyl binding (MBD) proteins can compensate for its absence [31,33,35].

In order to provide better understanding of MECP2 function, we characterized the distribution of the protein in more than 60 cell types of 16 mouse neuronal and non-neuronal tissues by immunostaining. We show that MECP2 is expressed at a very high level in all retinal neurons except rod photoreceptors. The onset of its expression during retina development coincides with massive formation of the neural synapses. We also describe the distribution of MECP2 in other tissues at various stages of development and relate its increased expression to the terminal differentiation of cells. Mice lacking MECP2 show no apparent defects in the morphology and development of the retina, as well as in the nuclear architecture of retinal neurons. Finally, we show that the absence of MECP2 is not compensated by upregulation of other MBD proteins but rather causes their downregulation.

\section{Results and discussion}

We studied mouse tissues because the nuclei of all mouse cells have prominent chromocenters which are convenient for the microscopic approach. The main DNA sequence of chromocenters, major satellite repeat, is present on all autosomes, comprises ca. 10\% of whole mouse DNA, contains ca. $50 \%$ of the CpG dinucleotides of the whole mouse genome [37], and was shown to bind MECP2 [1]. Therefore, chromocenters can serve as a sensitive indicator of MECP2 expression after immunostaining. To avoid interpretations which might depend only on chromocenters, in all relevant cases, we also studied rat tissues. In contrast to mouse, rat chromosomes do not have large blocks of pericentromeric repeats and therefore do not form noticeable chromocenters in interphase nuclei.

The standard methods of protein-level estimation, such as Western blot analysis routinely used for homogeneous cell cultures, are not really useful for native tissues containing various cell types. Therefore, our method of choice was MECP2 immunostaining on cryosections where we could distinguish different cell types using either histological criteria or cell-specific antibodies (Tables 1 and 2). To avoid false-positive and false-negative results after antibody staining, we used a robust and reliable method developed by us earlier $[38,39]$. This method allows quick comparison of immunostaining results in the same tissue after various fixation and antigen retrieval times. Polyclonal anti-MeCP2 antibodies, mostly used in the study, do not produce nuclear staining in fibroblasts derived from MECP2-deficient mice (Additional file 1A) and, when applied to Western blot, show expected enrichment of the protein in brain tissue derived from wild-type (WT) mice (Additional file 1B).

\section{MECP2 in retinal cell types}

The retina is an attractive model to study the role of MECP2 in a nerve center. Most of the retinal cell types can be recognized by their positions and by the shape of their nuclei; only in a few cases, identification requires cell type-specific immunostaining. Most of the mouse retinal cells express MECP2: their nuclei possess a weak or moderate staining of the nucleoplasm and a strong signal in chromocenters. In particular, all neurons in the ganglion cell layer (GCL), inner nuclear layer (INL), and cone photoreceptors in the outer nuclear layer (ONL) have very strong chromocenter staining and a weak nucleoplasm staining (Figure 1A). 
Table 1 List of antibodies for cell type identification in retina and brain and for recognition of retinal structures

\begin{tabular}{|c|c|c|c|}
\hline Antibody abbreviation & Antigen transmitter/protein & Recognized cells/structures & Source, catalogue number \\
\hline ChAT & Choline acetyl transferase & Cholinergic amacrine cells & Millipore, AB144P \\
\hline Calbindin & Calcium-binding protein $28 \mathrm{kD}$ & Horizontal cells & SWANT, \#300 \\
\hline GFAP & Glial fibrillary acidic protein & Astroglia & Sigma, G 3893 \\
\hline GABA & Gamma aminobutyric acid & Amacrine, horizontal cells & Sigma, A 2052 \\
\hline GABA-A a1 & GABA receptor subunit a1 & $\begin{array}{l}\text { Bipolar, amacrine, and ganglion } \\
\text { cell processes in IPL }\end{array}$ & Millipore, \#06-868 \\
\hline GABA-C & GABA receptor subunit $\rho 1$ & Synapses in IPL & R. Enz, MPI for Brain Research, Frankfurt \\
\hline GAT & GABA transporter & Presynaptic terminals & Abcam, ab426 \\
\hline GAD-65 & $\begin{array}{l}\text { Glutamic acid decarboxylase } \\
\text { (GABA-synthesizing enzyme) }\end{array}$ & Amacrine, horizontal cells & Chemicon, MAB351R \\
\hline GAD-67 & $\begin{array}{l}\text { Glutamic acid decarboxylase } \\
\text { (GABA-synthesizing enzyme) }\end{array}$ & Amacrine, horizontal cells & Abcam, ab26116 \\
\hline GS & Glutamine synthetase & Müller cells (astroglia) & BD Biosciences, \#610517 \\
\hline GluR3 & $\begin{array}{l}\text { Glutamate-gated ion channel } \\
\text { (glutamate receptor } 3 \text { ) }\end{array}$ & Synapses in IPL and OPL & Santa Cruz, sc-7612 \\
\hline GlyT1 & Glycine transporter 1 & Amacrine cells & Chemicon, AB1770 \\
\hline Iba 1 & $\begin{array}{l}\text { lonized calcium binding adaptor } \\
\text { molecule } 1\end{array}$ & Microglia/macrophage & Wako, \#019-19741 \\
\hline MAP2 & Microtubule-associated protein 2 & Neurons & Sigma, M1406 \\
\hline NR1C2 & NMDA receptor 1 splice variant C2 & IPL and OPL synapses & Chemicon, AB5050P \\
\hline PKCa & Protein kinase $\mathrm{C}$ & Rod bipolar cells & Sigma, P 4334 \\
\hline PKA $\| \beta$ & $\begin{array}{l}\text { Human protein kinase A, regulatory } \\
\text { subunit II beta }\end{array}$ & Cone bipolar cells & BD Biosciences, \#54720 \\
\hline PSD-95 & Postsynaptic density protein 95 & $\begin{array}{l}\text { Photoreceptors (rods and cones) } \\
\text { synapse marker }\end{array}$ & Dianova, MA1-046 \\
\hline SV2 & Membrane of synaptic vesicles & General synapse marker & DSHB, SV2-a1 \\
\hline $\mathrm{TH}$ & Tyrosine hydroxylase & Dopaminergic amacrine cells & Immunostar, \#22941 \\
\hline VGLUT1 & Vesicular glutamate transporter 1 & IPL and OPL synapses & Millipore, MAB5502 \\
\hline VGLUT3 & Vesicular glutamate transporter 3 & Amacrine cells & Millipore, AB5421 \\
\hline Znp-1 (Syt2) & Synaptotagmin II & Cone bipolar cells & $\begin{array}{l}\text { Zebrafish International Resource Center, } \\
\text { University of Oregon, Eugene, OR, Znp-1 }\end{array}$ \\
\hline
\end{tabular}

Millipore (Billerica, MA, USA), Swant (Marly, Switzerland), Sigma-Aldrich (St. Louis, MO, USA), Abcam (Cambridge, UK), Chemicon (Billerica, USA), BD Biosciences (Franklin Lakes, NJ, USA), Santa Cruz (Dallas, TX, USA), Wako (Richmond, VA, USA), Dianova (Hamburg, Germany), DSHB (University of lowa, IA, USA).

In contrast to other retinal cells, rod photoreceptor nuclei of nocturnal mammals possess a dramatically different pattern of chromatin distribution [30]. In these cells, a centrally positioned chromocenter is surrounded by a shell of LINE-rich heterochromatin, whereas

Table 2 List of antibodies for cell type identification in tissues other than the retina

\begin{tabular}{lcc}
\hline Cell type & Protein & Source, catalogue number \\
\hline Smooth muscles & Calponin & Abcam, ab46794 \\
Paneth cells & Lysozyme & Dako, A 0099 \\
Enteroendocrine cells & Secretin & Santa Cruz, sc-26630 \\
Goblet cells & Mucin-2 & Santa Cruz, sc-15334 \\
Satellite cells & Pax 7 & DSHB \\
\hline
\end{tabular}

Dako (Troy, MI, USA). euchromatin occupies the nuclear periphery. This nuclear organization is inverted in comparison to all other eukaryotic cells possessing conventional nuclear architecture with heterochromatin abutting the nuclear periphery and euchromatin located in the nuclear interior $[28,30]$. We have shown that the inverted nuclear architecture in rods has evolved as an adaptation to nocturnal vision: the heterochromatic cores of rod nuclei function as microlenses and reduce light scatter in ONL [30]. Unexpectedly, the nucleoplasm of the inverted rod nuclei is not stained by anti-MECP2 antibodies, and the central chromocenter is only weakly positive (Figure 1A).

In comparison to the multiple chromocenters characteristic of other mouse cell types, the single central chromocenter in mouse rods has a superior chromatin density, which is necessary for rod nuclei to function as microlenses 

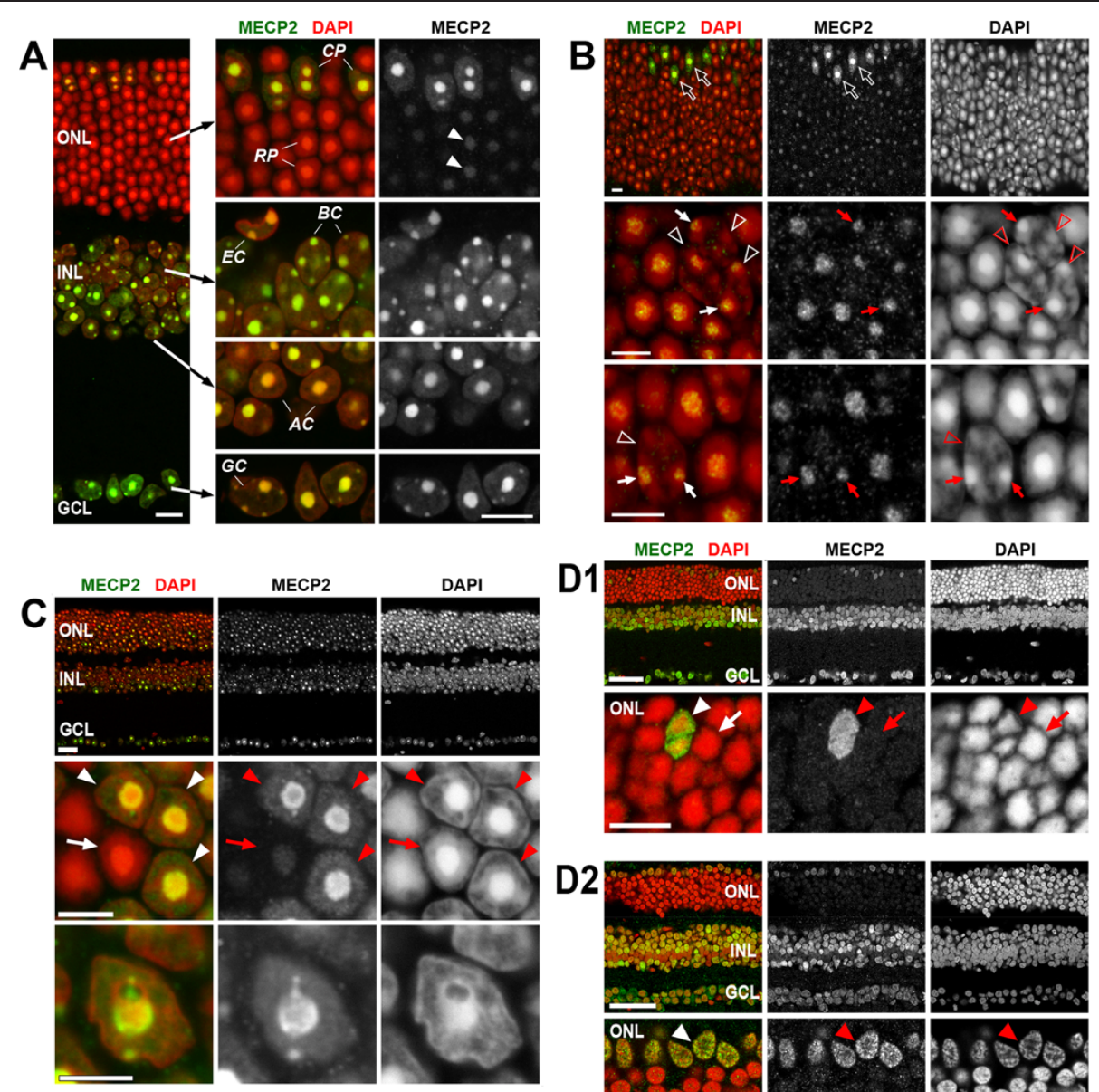

MECP2

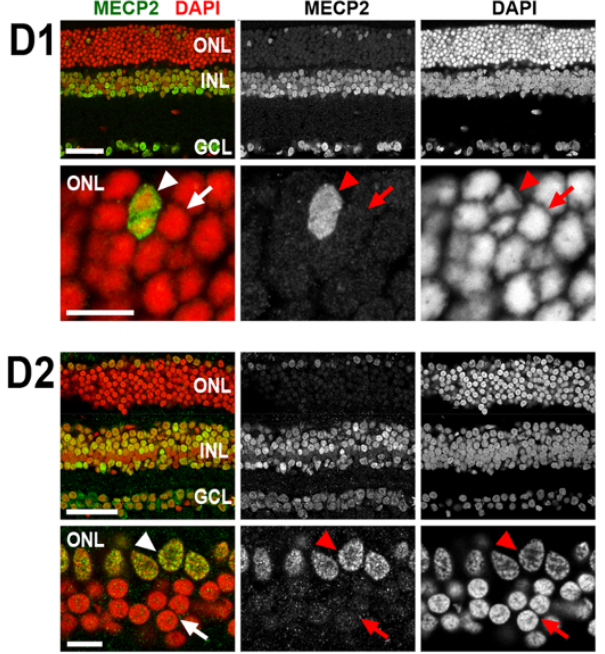

Figure 1 Distribution of MECP2 in the nuclei of retinal cells. (A) MECP2 is abundant in all retinal neurons: in the ganglion cell layer (GCL), inner nuclear cell layer (INL), in bipolar (BC) and amacrine (AC) cells. The signal is present throughout the whole nucleoplasm but is especially strong in chromocenters. In the ONL of adult mice, MECP2 produces a strong signal in cone photoreceptors (CP) whereas rod photoreceptors (RP) have very weak staining only noticeable in the chromocenters (arrowheads). (B) Restoration of conventional nuclear architecture in rod nuclei by Lbr expression in Lbr-TER mice does not increase MECP2 expression. In Lbr-expressing rods (three such nuclei are marked by empty arrowheads), there are multiple chromocenters adjacent to the nuclear periphery. These chromocenters (arrows) remain weakly MECP2-positive and with the staining intensity comparable to that of chromocenters in inverted nuclei not expressing Lbr. For comparison, bright staining of cone nuclei (empty arrows, left and middle upper panels) is shown. Note that all rods with multiple chromocenters adjacent to the nuclear periphery express Lbr (Solovei et al. [41]); LBR staining is not shown on this panel. (C) In R7E mice, rods de-differentiate, partially restore the conventional architecture of their nuclei, and lose their rod identity. This process is accompanied by increased expression of MECP2 which becomes abundant in chromocenters (three such nuclei are marked by arrowheads) and reaches the same level as in neuroretina (upper panel). For comparison, an unaltered rod nucleus is marked (arrow). (D) Retina of rat (D1) and macaque (D2). Similarly to mice, MECP2 produces a bright signal in the GCL, INL, and cones (arrowheads) but is weak to undetectable in rod

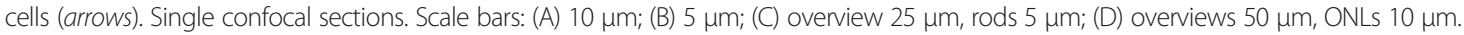

[30]. This high chromatin compaction is obvious from recent electron microscopic studies (e.g., Figure two in [38] and Figure three panel $\mathrm{a}$ in [40]) and from the dramatic difference in immunostaining properties between rod chromocenters and chromocenters of other retinal neurons. As described in detail in the recent immunohistochemical studies [38-40], the chromocenter in rods requires much longer antigen retrieval in comparison to the neighboring cones and INL cells. Therefore, to rule out that weak MECP2 staining is caused by inaccessibility of chromocenter chromatin to the antibodies, we made use of transgenic mouse retinas in which rod cells ectopically express lamin $B$ receptor (LBR). Rods expressing transgenic LBR acquire conventional nuclear architecture with euchromatin located to the nuclear interior and heterochromatin, including multiple chromocenters, located at the nuclear periphery. Chromocenters of these transgenic rods have apparently lower chromatin compaction and restore immunostaining ability typical for other retinal cells [41]. However, despite their reduced size and density, chromocenters in LBRexpressing rods remain as weakly MECP2-positive as the chromocenters of wild-type rods (Figure 1B). 
The above observations are consistent with results of MECP2 staining in photoreceptors of R7E mice [42]. These transgenic mice specifically express CAG trinucleotide repeat encoding a polyglutamine stretch and represent a mouse model to study spinocerebellar ataxia type 7 (SCA7). In R7E mice, mature rods with inverted nuclei begin to de-differentiate in ca. 1-monthold animals, their nuclei partially restore a conventional nuclear architecture, and photoreceptors lose their rod identity [42]. MECP2 expression in R7E rods gradually increases in parallel to the de-differentiation, and at the age of 20 weeks, the MECP2 level in chromocenters reaches the level observed in the other neurons of the retina (Figure $1 \mathrm{C}$ ).

Furthermore, we also tested for the presence of MECP2 in rods of two other mammalian species: (i) rat, a nocturnal mammal without chromocenters; and (ii) macaque, a diurnal primate with conventional nuclear architecture in rods. In both species, MECP2 was undetectable in rods, in a prominent difference to neuroretinal cells and cone photoreceptors where it produced a clear signal (Figure 1D). Taken together, the above data imply that weak expression of MECP2 is an intrinsic feature of rod photoreceptors.

The low level of MECP2 in rods can be tentatively connected to the relatively high level of linker histone $\mathrm{H} 1 \mathrm{c}$ in rod cells described recently for mouse rod photoreceptors [43]. It has been shown that in the MECP2-rich neurons of the brain, approximately half of the linker histone $\mathrm{H} 1$ tends to be replaced by MECP2, and that in Mecp2-null mice, the $\mathrm{H} 1$ level in these neurons doubles [27]. Remarkably, triple KO mice deficient in linker $\mathrm{H} 1 \mathrm{c} / \mathrm{H} 1 \mathrm{e} / \mathrm{H} 10$ histone variants show significant increase of the rod nuclear diameter which was accompanied by decrease of the nuclear volume occupied by heterochromatin. These changes in the nuclear architecture were noticed only in rod nuclei [40]. The other way around, in de-differentiated rods of R7E mice, which demonstrate significantly reduced level of H1c [44,45], the expression of MECP2 increases (Figure 1C).

\section{Microglial cells have no detectable MECP2}

Non-neuronal cells of the retina-pigment epithelium, endothelial cells of blood vessels, and Müller cells (radial astroglia)-also expressed MECP2. The only exception was microglia where MECP2 was never detected by immunostaining (Figure 2A). Moreover, microglial cells, identified using anti-lbal antibodies, were negative for MECP2 staining not only in the retina but also in the brain, cerebellum and spinal cord (Figure 2A). In contrast, in astroglial cells (Figure 2B) and neurons (Figure 2C1, $\mathrm{C} 2$ ), nuclei are strongly positive after MECP2 staining. Absence of MECP2 in microglial cells revealed by immunostaining is especially intriguing in view of recent data on the involvement of microglial cells in the Rett phenotype [46] and questions the role of these cells in neuropathologic consequences of MECP2 deficiency. On the other hand, sensitivity of immunostaining is unquestionably lower than most of biochemical in vitro approaches, and therefore, one cannot wholly exclude that microglia cells express MECP2 at a level not detectable microscopically.

\section{Retinas of Mecp2-null mice show no apparent defects}

Absence of MECP2 impairs neuronal morphology and strongly affects functions of the brain [9]. The retina, as a compact and very regularly structured part of the CNS, represents an attractive model to study the possible effects of MECP2 on the nervous system development. Earlier, it was shown that in Mecp 2 knockout mice, decline in visual acuity, which was observed in late postnatal development, is caused by general silencing of the cortical circuitry [47]. However, major morphological characteristics of retinas in MECP2-deficient mice have not been yet reported. We dissected retinas of $M e c p 2^{-/ y}$ mice at different stages of retina maturation, at postnatal days P1, P7, P13, P30, and P53, and compared their histology to the retinas of wild-type littermates. We found that $M e c p 2^{-/ y}$ and WT retinas were not different with respect to the time of layer formation, thickness, and morphology of the layers at all five studied developmental stages (Additional file 2). In addition, we compared $M e c p 2^{-/ y}$ and $M e c p 2^{w t}$ retinas with respect to the distribution of various retinal markers. Twelve immunocytochemical markers specific for various amacrine, bipolar, ganglion, and horizontal cells, seven markers for inner plexiform layer (IPL) or/and outer plexiform layer (OPL), and markers for radial glia (Müller cells) and microglia (Table 1) were applied to retinas from adult $M e c p 2^{-/ y}$ and WT littermate mice. As shown in Figure 3A and Additional file 3, no noticeable differences in the distribution of certain neurons, synapses, and neurotransmitters were found between the two genotypes.

\section{Nuclear architecture of neuronal nuclei in Mecp2-null mice is generally preserved}

Since MECP2 is a methylation reader and apparently involved in heterochromatin formation $[27,36]$, we checked whether its absence causes changes in the epigenetic landscape of rod and other retinal nuclei. We found that MECP2 deficiency did not have any microscopically visible effect on the presence and distribution of major histone modifications (Table 3). In Mecp $2^{-/ y}$ mice, euchromatin marked by acetylated H3, H4, H3K9ac,me1, and H4K20ac, me1 was present in the nuclear interior of GCL and INL cells and in the outermost peripheral shell of rod nuclei, just as it was observed in WT mice (Figure 3B, Additional file 4). The presence of histone modifications H3K9me2,3 and H4K20me2,3, characteristic of heterochromatin, was restricted to the nuclear periphery and chromocenters 


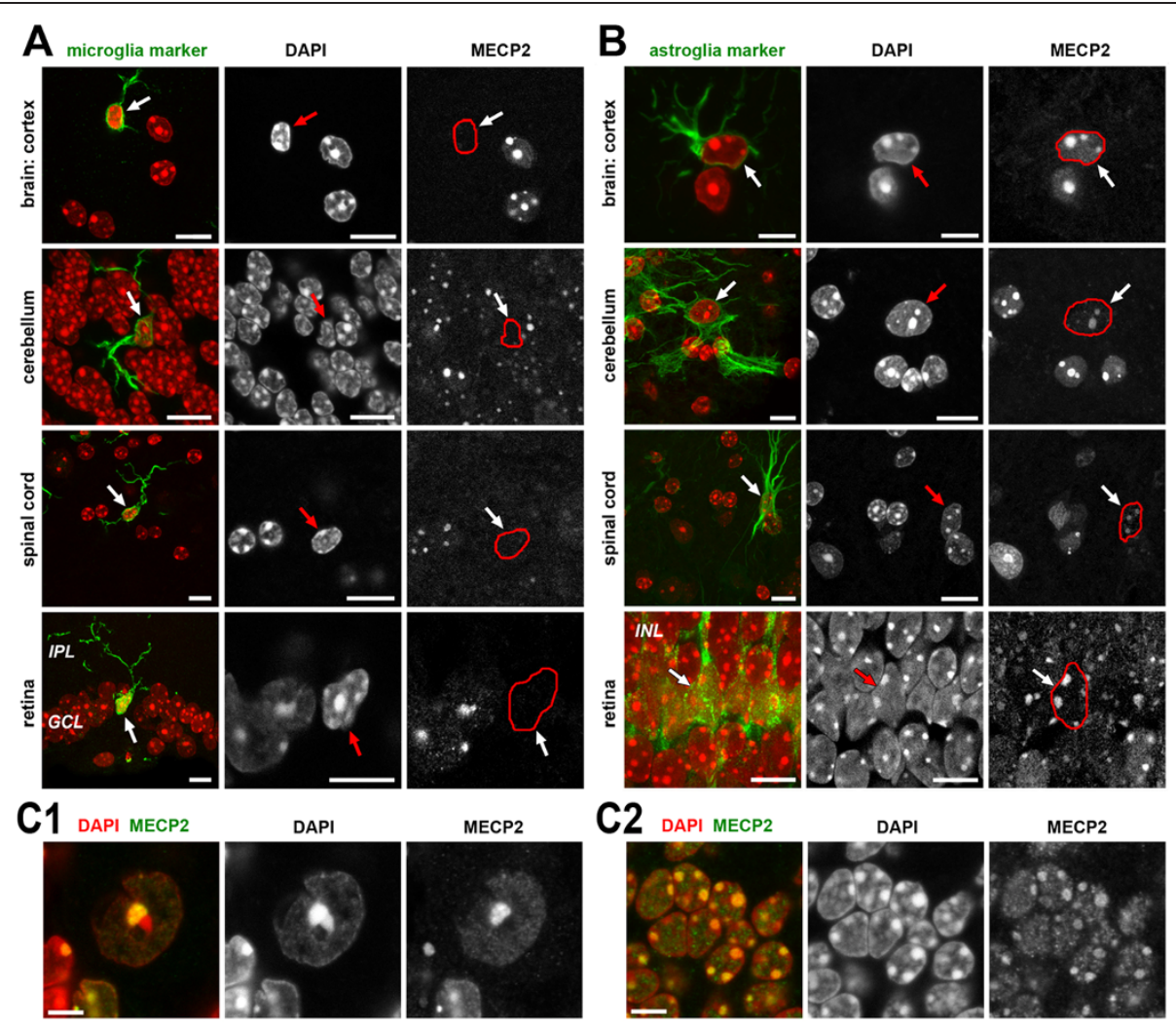

Figure 2 Microglial cells (A) have no detectable MECP2 compared to astroglia (B) and neurons (C). (A, B) MECP2 detection in brain cortex, cerebellum, spinal cord, and retina combined with microglial (A) and astroglial (B) cell type-specific staining. Overlays of 4',6-diamidino-2-phenylindole (DAPI) staining (red) with markers for microglia (Iba-1) and astroglia (GFAP) are shown in left columns as projections of short stacks. Middle and right columns show single optical sections (zoomed in) for DAPI and MECP2. Non-marked cells in the same images are predominantly neurons and strongly express MECP2. Red outlines in the right column images trace the shape of the nuclei of interest. (C) Neurons from cerebellum - Purkinje cells (C1) and granular cells (C2) demonstrate strong MECP2 staining in chromocenters and moderate staining of the nucleoplasm in a single confocal section. Scale bars: (A,B) $10 \mu \mathrm{m},(C) 5 \mu \mathrm{m}$.

of neuroretina cells and was also not different from the wild-type (Additional file 4; see also [38]).

Conversely, we checked whether erasing of the major heterochromatin hallmarks, H3K9me2,3 and H4K20me3, would prevent MECP2 binding. For this purpose, we studied retinas from mice lacking H4K20me3 due to deletion of Suv4-20 h2 and mice lacking both H4K20me3 and H3K9me3 due to deletion of Suv4-20 and Suv3-9 h1,2 methyltransferases. In mice of both genotypes, rod nuclei had the same morphology as the rod nuclei in the wildtype littermate controls [38]. We found that the pattern of MECP2 staining was not different between the retinal cells in the wild-type and knockout mice, suggesting that MECP2 binding to chromatin was not affected. Indeed, MECP2 was strongly expressed in neuroretina and cones, where it localizes mostly in chromocenters, and was almost undetectable in rods (Additional file 5). Recently, it was shown that deletion of Suv4-20 h2 influences chromatin organization in cultured cells, in particular, it increases the number of chromocenters in cultured fibroblasts derived from a Suv3-9/Suv4-20 h double knockout mouse [48]. In contrast, double knockout of Suv3-9 and Suv4-20 affects neither rod nuclear morphology [38] nor MECP2 binding patterns (this study), suggesting that cells in a tissue context might have more redundancy in epigenetic mechanisms than cultured cells.

Although even a complete loss of MECP2 does not prevent chromocenter formation in mouse cells [8], observations on astroglial cells and neurons differentiated from embryonic stem cells in vitro showed that the number of chromocenters was significantly higher in MECP2-null cells compared to wild-type cells [36]. The other way around, ectopic expression of MECP2 induces clustering and fusion of chromocenters, a process which takes place during myotube differentiation [31]. These findings prompted us to assess rod chromocenter numbers in adult mice of both genotypes. Chromocenter fusion in nuclei of mouse rods is a slow process. A significant proportion of rods at ca. 1 month still have two or more chromocenters; their fusion in all rods is completed only at $2-2.5$ months of age $([30,41]$; c.f. Figure $3 C 2, C 3)$. We scored cells with one 

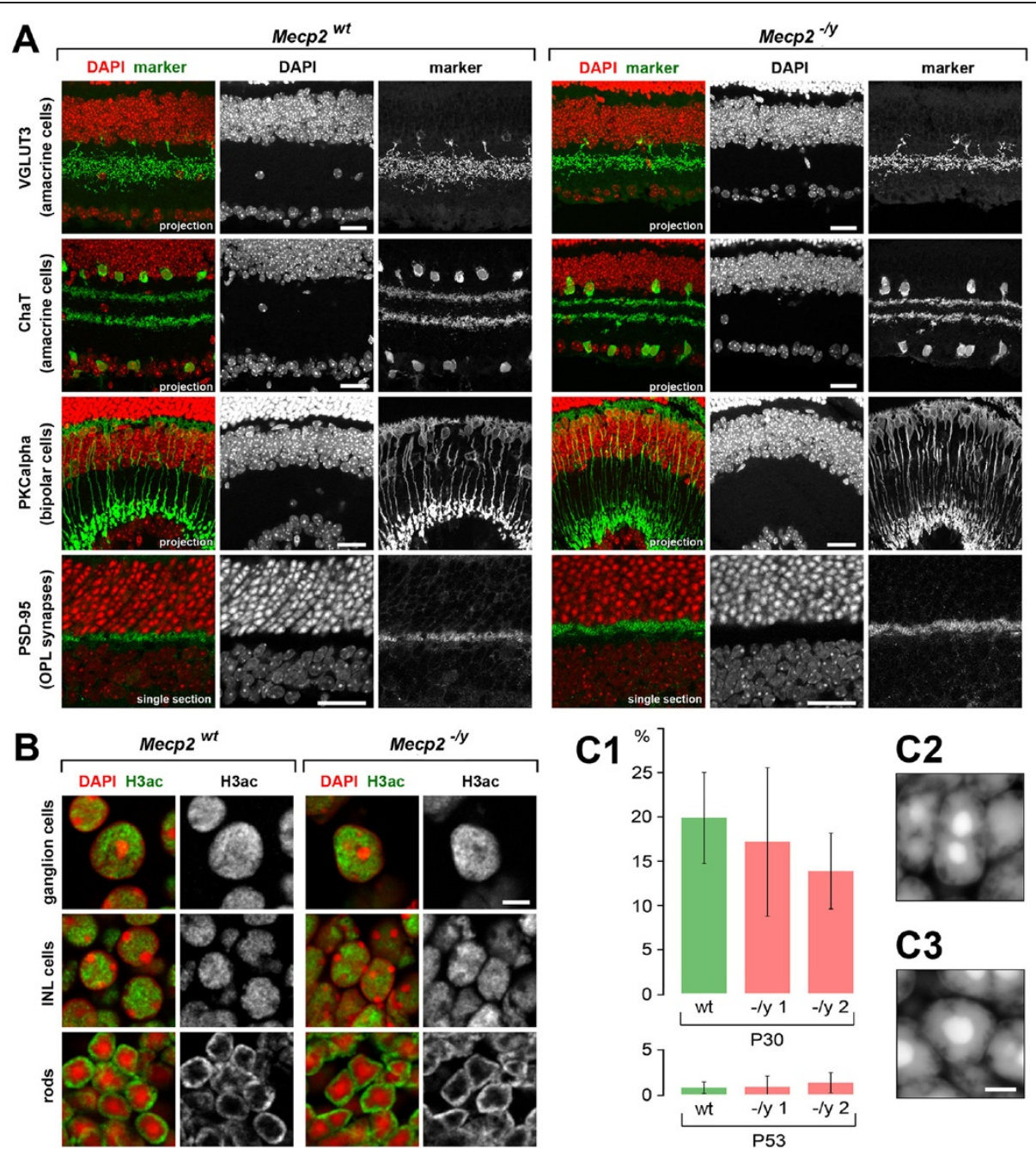

C2
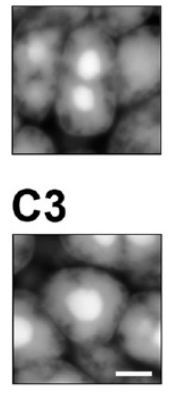

Figure 3 Retinas of $M e c p 2^{-/ y}$ mice show no apparent defects. (A) Positioning of amacrine cells, rod bipolar cells, and photoreceptor synapses is similar in retinas of Mecp2 $2^{-1 y}$ and Mecp $2^{\text {loxy }}$ littermates. Other 14 markers for retinal cell types, synapses, and neurotransmitters are shown in Additional file 2. (B) Similar distribution of a histone modification typical of euchromatin (H3ac) in Mecp $2^{-1 y}$ and Mecp $2^{\text {wt }}$ littermate retinas; nuclei with conventional (ganglion and INL cells) and inverted (rods) architecture are shown. (C) The proportions of rod nuclei with two or more chromocenters were scored in retinas of two Mecp2 ${ }^{-y}$ and one Mecp $2^{\text {wt }}$ littermate at two age points, P30 and P53 (C1). At P53, nearly all nuclei have a single chromocenter. Average proportions of rods with two or less chromocenters were not significantly different between the two genotypes. Errors bars are the 95\% confidence intervals. Rod nuclei with two (C2) and one (C3) chromocenter. Scale bars: (A) $25 \mu \mathrm{m}$, (B) $5 \mu \mathrm{m},(\mathrm{C}) 2 \mu \mathrm{m}$.

and two chromocenters in rod nuclei of $M e c p 2^{-/ y}$ mice and their wild-type littermates at P30 and P53 (see the 'Methods' section for detailed description). The number of rods with two or more chromocenters in $M e c p 2^{-/ y}$ mice of these ages was $15.5 \%$ at P30 and $1.2 \%$ at P53, which was not different from the wildtype (Figure $3 \mathrm{C} 1$ ).

In full agreement with our observations on rod cells, data obtained from cortical neurons in tissue sections and primary neuronal cultures indicate that chromocenter number is comparable between neurons from $\mathrm{Mecp}^{-/ y}$ and $M e c p 2^{+/ y}$ mice [35]. Apparently, the difference in results obtained on cells in native tissues of Mecp $2^{-/ y}$ and Mecp $2^{+/ y}$ mice and on cultured cells derived from these mice [36] is analogous to the observations on Suv3-9/Suv4-20 h double knockout cells and might be tentatively explained by compensatory mechanisms operating in vivo but not in vitro.

\section{Almost all cell types in adult mammalian tissues express MECP2}

The absence of MECP2 in microglia and its low level in rods raised the question of how common MECP2 is in various cell types. Data on MECP2 expression in different tissues are limited, and most reports are based on a bulk analysis of protein or RNA extracted from a whole tissue (e.g., $[49,50])$. Analyses of specific cell types are only occasional and predominantly concern neuronal tissues [49-51]. Therefore, we studied MECP2 distribution across 
Table 3 List of antibodies for histone modification detection

\begin{tabular}{lcc}
\hline Histone/residue & Modification & Source (catalogue number) \\
\hline H3K9 & Acetyl & HK (CMA310) \\
& Me1 & HK (CMA316) \\
& Me2 & HK (CMA317) \\
& Me3 & HK (CMA318) \\
H4K20 & Acetyl & HK (CMA420) \\
& Me1 & HK (CMA421) \\
& Me2 & HK (CMA422) \\
& Me3 & HK (CMA423) \\
H3 & Acetyl & Upstate (\#06-599) \\
H4 & Acetyl & Upstate (\#06-866) \\
\hline
\end{tabular}

HK produced in the laboratory of Hiroshi Kimura, Osaka University (Osaka, Japan). Upstate (Lake Placid, NY, USA).

a number of mouse cell types. Cell identification was based either on histological criteria or, when needed, on cell type-specific immunostaining (for the list of antibodies used, see Table 2). Altogether, about 60 cell types were studied from 12 non-neuronal adult mouse tissues. In addition, epidermis and skeletal muscles were studied at five age points (P0, P2, P5, P9, and P14). The results of immunostaining are summarized in Figure 4A, and telling examples are shown in Figure 4B,C,D,E,F,G,H. We found that the majority of cell types express MECP2; those that do not are rather a minority. MECP2 is lacking in epithelial cells of the intestine and colon. In epidermis, the expression of MECP2 varies: it is absent or present at a hardly detectable level in keratinocytes of the trunk skin but is more abundant in lip epidermis cells, both basal and suprabasal. In the hair, proliferating matrix keratinocytes of the hair bulb lack MECP2 in clear difference to differentiated keratinocytes of hair shaft and hair root sheath where MECP2 produces a clear signal. MECP2 is also not expressed in the erythropoietic lineage, in contrast to other cells of the myeloid lineage and lymphocytes. A noteworthy exception are resident macrophages. As mentioned before, microglial cells in all studied nervous tissues do not express MECP2 at a detectable level (Figures 2A and 4A), whereas resident macrophages from other tissues, in particular, hepatic Kupffer cells, do express it (Figure 4A,H).

As MECP2 is primarily visible in the chromocenters of mouse cells, we studied MECP2 distribution in tissues of a species, which does not possess chromocenters in interphase nuclei. Rat chromosomes, in difference to mouse chromosomes, lack large blocks of pericentromeric satellite sequences, and consequently, rat nuclei have no clear chromocenters. Rat small intestine, skin with hairs, and skeletal and heart muscles were studied. Staining of these tissues confirmed that the gastrodermal epithelial and hair matrix cells in rat, similarly to mouse, lack MECP2, whereas the nuclei of muscle cells (smooth, skeletal, and heart muscles) had a strong punctate MECP2 signal in the nucleoplasm (Figure 5). Our data support the notion that in addition to the functions in the nervous system that are associated with a major pathologic phenotype, MECP2 plays some important roles in almost all non-nervous tissues.

Involvement of MECP2 in chromatin regulation and maintenance of global nuclear architecture is well documented $[27,52,53]$. In particular, it is known that MECP2 plays a role in the regulation of transcription, being mostly a transcriptional repressor [54-56] and also an activator [54]. In the light of these findings, the fact that some cell types across different species are lacking MECP2 is intriguing and requires further analysis.

\section{Expression of MECP2 increases during tissue development and terminal cell differentiation}

There is a clear difference between MECP2 expression levels in tissues of different developmental stages. A telling example are fibroblasts of the dermal papilla in the hair bulb. These cells lack MECP2 at the late embryonic stages and in the first 2 days of postnatal development; the expression starts at P2 and continues afterwards (Figure 6D).

The expression of MECP2 in the retina starts at different times depending on the cell type. Remarkably, the onset of expression coincides with massive formation of synapses and, as a consequence, the formation of the IPL and OPL [57-59] (Figure 6A,B). In particular, MECP2 appears in the ganglion and amacrine cells at E17, when a clear gap appears between the GCL and INL + ONL anlage, marking the emerging IPL. Similarly, the MECP2 expression in the bipolar cells starts at P6 together with the formation of the gap between the INL and ONL, which develops into the OPL later. In rods, weak MECP2 expression starts after 2 weeks of postnatal development and remains weak thereafter (Figure 6A,C). Noteworthy, the onset of MECP2 expression roughly correlates with cell birthdays (the day of the last cell division; [60]) of the retinal neuronal cell types $\left(R_{\text {Spearman }}=0.62\right)$ and persists afterwards.

Initiation of MECP2 expression at late differentiation stages proved to be a general rule: undifferentiated or weakly differentiated cells (progenitors) do not express MECP2 or show a low expression level compared to the respective fully differentiated cells. In particular, matrix keratinocytes of the hair bulb do not express MECP2, the more differentiated keratinocytes of the hair shaft show a weak expression, and a stronger expression is observed in the keratinocytes at the root hair shaft. MECP2 is weak in satellite cells but abundant in the myotube nuclei (Figure 4A,F). The reverse situation occurs only in the gonads. In the ovaries, the follicle epithelium and the 


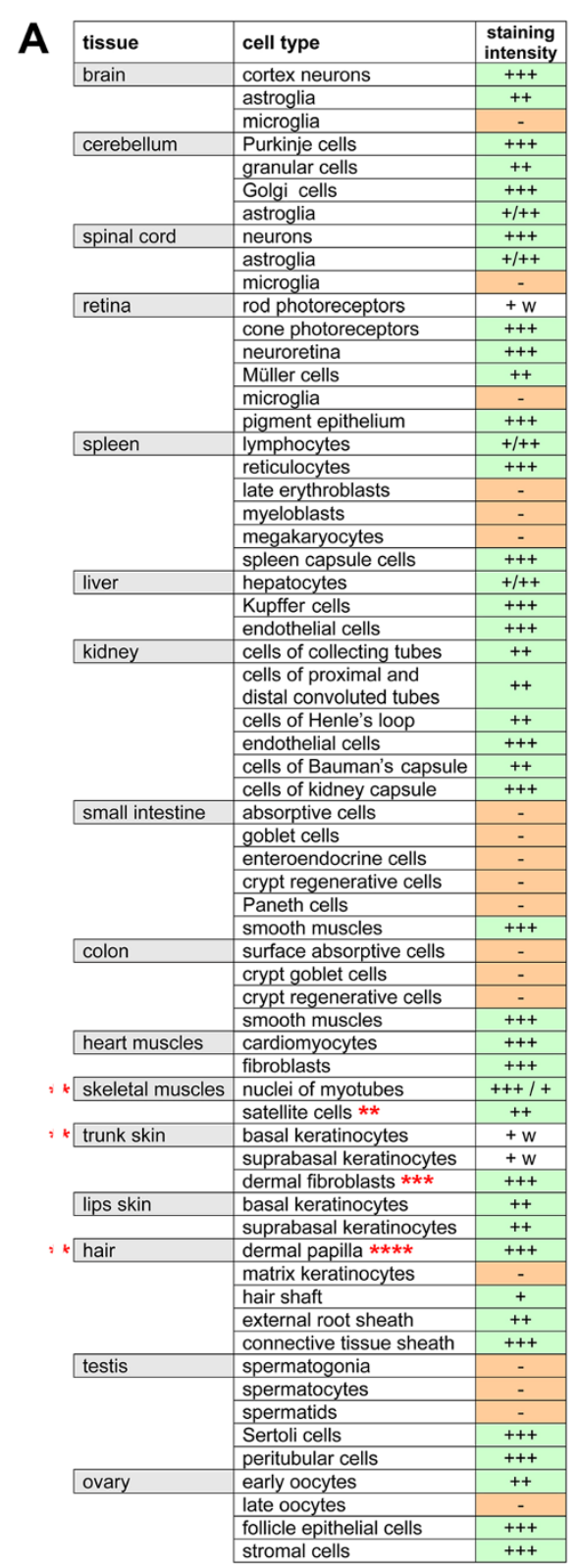

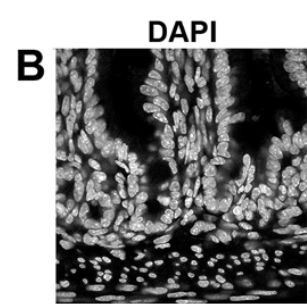
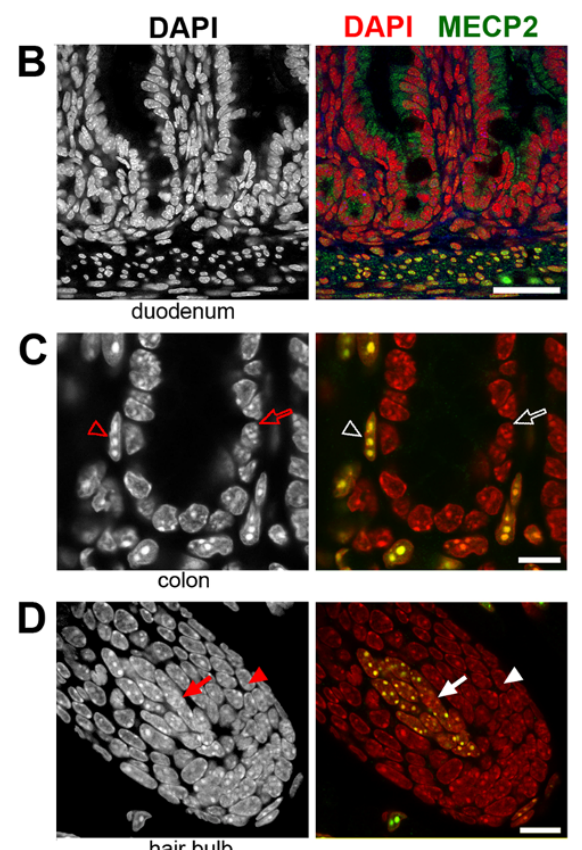

E
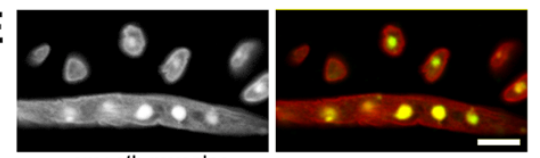

F

smooth muscles
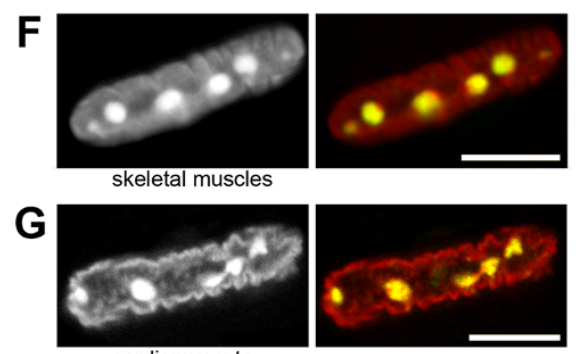

H
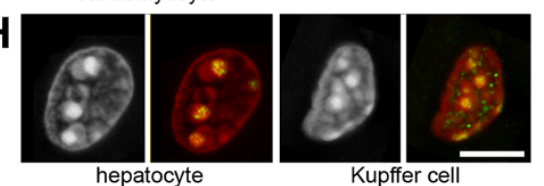

Figure 4 Presence of MECP2 in different cell types of adult mouse tissues. (A) List of the studied tissues and cell types; the strength of MECP2 signal is shown by the number of plus signs (1 to 3). * Tissues studied at six developmental age points (P0, P2, P5, P9, and P14). **Satellite cells were negative at P0-P14. ***Dermal fibroblasts were negative at P0-P5. ${ }^{* * * * F i b r o b l a s t s ~ o f ~ d e r m a l ~ p a p i l l a ~ w e r e ~ n e g a t i v e ~ a t ~ P 0 ~ a n d ~ w e a k l y ~ p o s i t i v e ~ a t ~}$ P2; see also Figure 5D. Examples of mouse tissues after MECP2 staining: intestine (B, C), hair (D), muscles (E, F, G), and liver (H). In (C), empty arrows point at MECP2-negative gastroepithelial cells in colon crypt; empty arrowheads point at positive smooth muscle nucleus beneath the gastrodermis. In (D), solid arrows mark fibroblasts of the dermal papilla; solid arrowheads mark matrix keratinocytes of the hair bulb. For comparison of MECP2 staining in mouse and rat tissues, see Additional file 4. Single confocal sections. Scale bars: (B) $50 \mu \mathrm{m},(C, D) 10 \mu \mathrm{m},(E, F, G, H) 5 \mu \mathrm{m}$.

youngest oocytes express MECP2, whereas mature oocytes do not (Figure 7A). Sertoli cells and fibroblasts are MECP2 positive, whereas spermatogenic cells do not express MECP2 at any stage (Figure 7B). The absence of MECP2 immunostaining in mature gametes conforms to the known fact that zygotes, stem cells, and cells of young embryos [61-63] lack MECP2. In summary, our results indicate that MECP2 is a marker of the differentiated state.
Absence of MECP2 is not compensated by altered expression of other MBD proteins in cultured cells and native tissues

Considering the specific binding of MECP2 to methylated DNA, we questioned whether other proteins are able to replace MECP2 on 5-methylcytosine $(5 \mathrm{mC})$ in case of its absence. Though this has not been systematically investigated, the question has been addressed genetically 

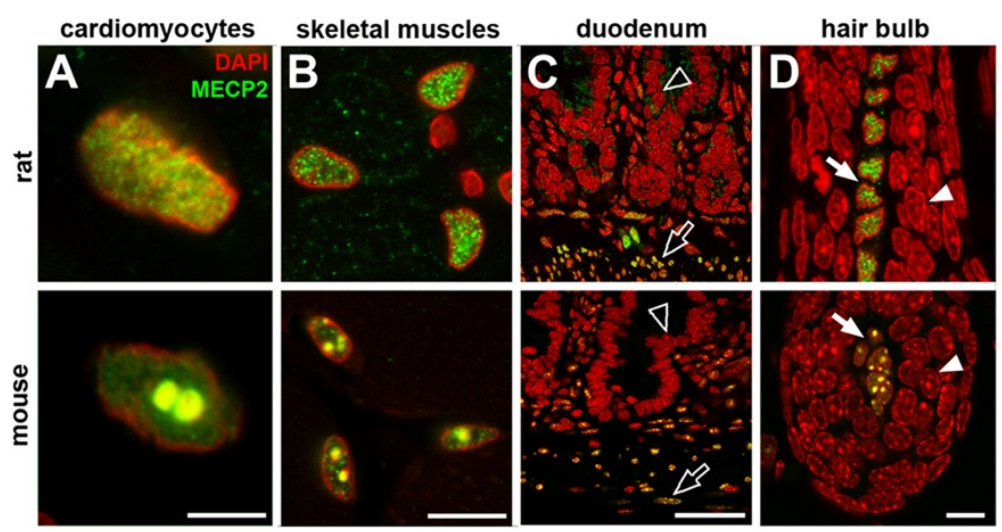

Figure 5 Comparison of MECP2 staining in selected mouse and rat tissues. Nuclei of striated muscle cells (A, cardiomyocytes; B, skeletal myotubes), smooth muscles (C, empty arrows in duodenum), and fibroblasts of dermal papilla (D, solid arrows) have strong MECP2 signal in both species. Similarly, gastrodermal epithelial cells (empty arrowheads) and matrix keratinocytes (solid arrowheads) lack MECP2 in both species. Single confocal sections. Scale bars: (A) $5 \mu \mathrm{m}$, (B, D) $10 \mu \mathrm{m}$, (C) $25 \mu \mathrm{m}$.

by Caballero and co-authors [64]. The authors showed that simultaneous deficiency of three methyl-CpG binding proteins MECP2, MBD2, and KAISO in mice is compatible with normal embryogenesis and provided evidence for redundancy of function between these proteins in postnatal mice. Since antibodies to other methyl-CpG binding proteins reliably working on cryosections are lacking, we quantitatively studied the expression level of all known $5 \mathrm{mC}$-binding proteins in $M e c p 2^{-/ y}$ cultured cells and tissues by reverse transcription quantitative polymerase chain reaction (RT-qPCR). We focused on an expression analysis of the following methyl binding proteins: four MBD proteins, MBD1, MBD2, MBD3, and MBD6 (MBD4 and MBD5 were omitted due to the nearly undetectable expression level); UHRF1 and UHRF2; SETDB1; and three methyl-CpG binding zinc finger proteins, namely, ZBTB33, ZBTB38, and ZBTB4. First, we analyzed the expression of all the above genes in adult $M e c p 2^{-/ y}$, adult $M e c p 2^{l o x / y}$, and embryonic wildtype fibroblasts. The analyzed genes were transcribed at different levels in embryonic and adult fibroblasts. In particular, we noted a statistically significant decrease in the expression of $M b d 1$ and Mbd6, Uhrf1 and Uhrf2, Zbtb33 and Zbtb4, and Setdb1 in the embryonic fibroblasts compared to the adult cultured fibroblasts. However, we found no apparent difference in gene expression between the adult $M e c p 2^{l o x / y}$ and $M e c p 2^{-/ y}$ fibroblasts (Figure 8A). Similarly, comparison of gene expression in the skeletal muscle, heart, and small intestine did not reveal any differences between tissues from Mecp $2^{-/ y}$ and $M e c p 2^{w t}$ mice (Additional file 6). Unexpectedly, in the $M e c p 2^{-/ y}$ brain and liver, the expression of these proteins (e.g., MBD2) was even significantly decreased (Figure $8 \mathrm{~B}, \mathrm{C}$ ). Thus, we demonstrated that absence of MECP2 is not compensated by any other known $5 \mathrm{mC}$ binding protein at least at the mRNA level.

\section{Conclusions}

Based on the above discussion, the following conclusions were made:

- All retinal neurons, except rods, express MECP2 at a high level and the onset of its expression coincides with neuron differentiation, in particular, with massive formation of neural synapses in the inner and outer plexiform layers.

- Low expression of MECP2 in rod photoreceptors was found in both the inverted rod nuclei of nocturnal mammals and the conventional rod nuclei of diurnal mammals. We relate this fact to an unusually high level of histone H1c in these cells in comparison to other retinal neurons [43].

- MECP2 is not detectable by immunostaining in the retinal microglial cells, nor in the microglia of the cortex, cerebellum, and spinal cord. In contrast to microglia, the astroglial cells in all neuronal tissues express MECP2 at a level comparable to that in neurons.

- The retina of Mecp2-null mice shows no apparent defects in the timing and morphology of the nuclear and plexiform layer formation. No noticeable difference in the distribution of certain neuron types, synapses, and neurotransmitters was found between Mecp2-null and wild-type retinas.

- The nuclear architecture of the neuroretinal cells and rod photoreceptors is generally preserved in Mecp2-null mice; in particular, there are no obvious changes in the distribution of pericentromeric heterochromatin and major epigenetic markers characteristic for eu- and heterochromatin.

- MECP2 is expressed in the majority of studied 64 non-neuronal cell types; cells which do not express MECP2 are epithelial cells of the intestine, cells of 


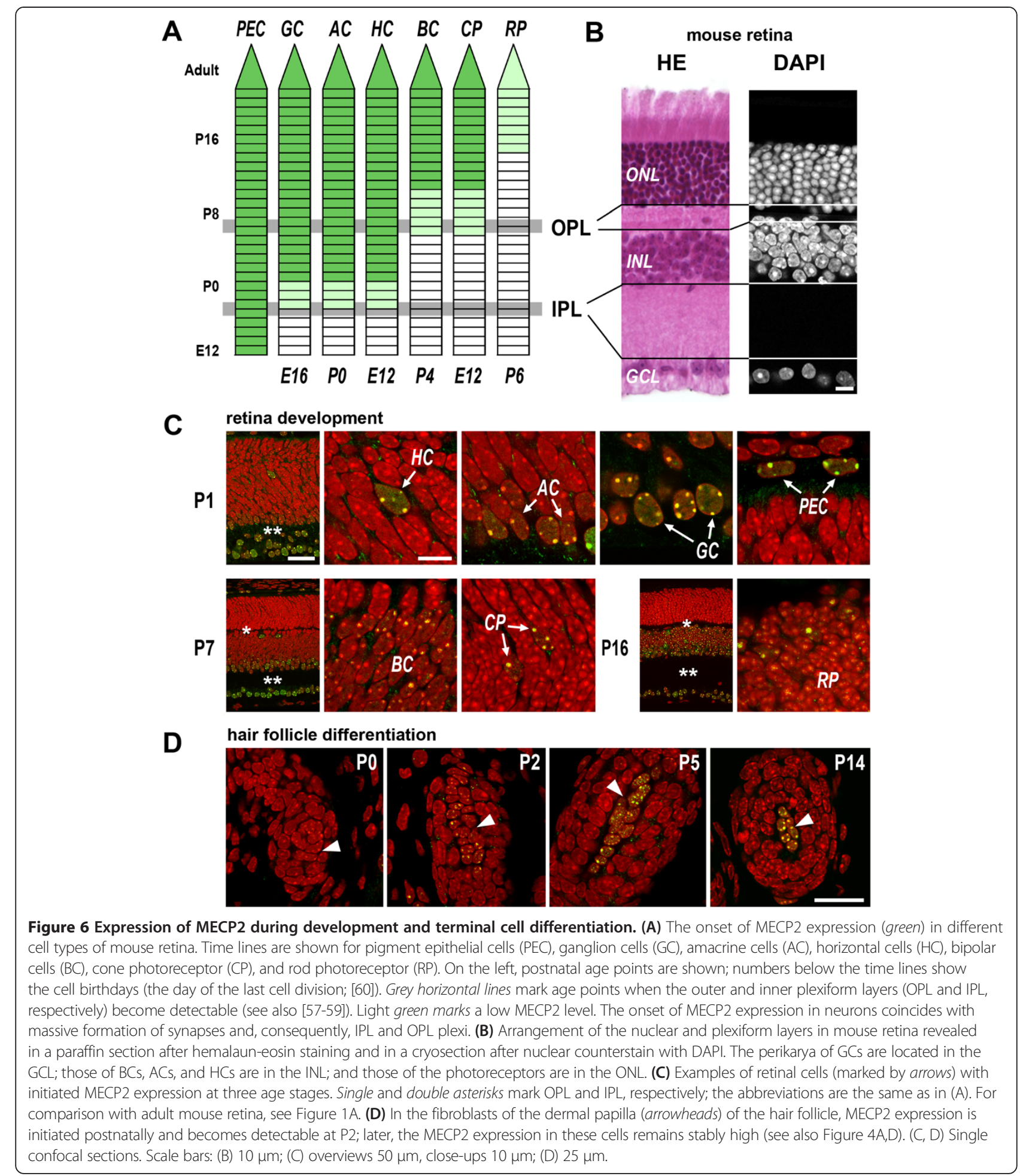

the erythropoietic lineage, hair matrix keratinocytes, and mature gonads; epidermis keratinocytes express MECP2 at a very low level.

- Similarly to neurons, the expression of MECP2 in non-neuronal cells is initiated at the late differentiation stages; in this respect, gonads show a reverse pattern with no expression in differentiated oocytes and spermatozoids.

- An absence of MECP2 is not compensated by increased expression of other methyl binding proteins; in contrast, expression of some of them was downregulated. 

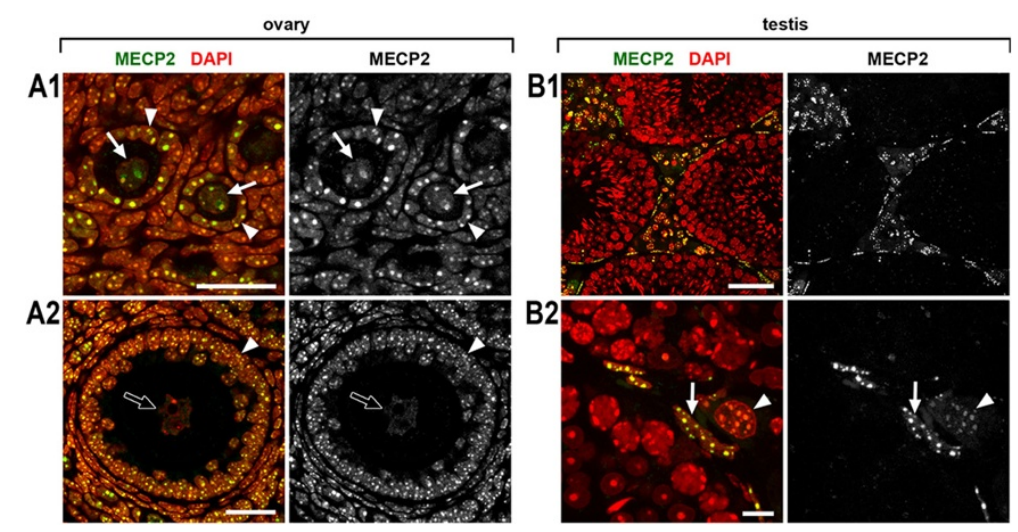

Figure 7 Expression of MECP2 in the ovary (A) and testis (B). Only young oocytes (A1, arrows) express MECP2; the more mature oocytes (A2) do not express MECP2 (A2, empty arrow). Neighboring follicular cells (arrowheads) strongly express MECP2. In testis, only Sertoli cells (B2, arrowhead) and fibroblasts (B2, arrows) express MECP2; spermatocytes at all stages of maturation and sperm cells are MECP2-negative. Single confocal sections. Scale bars: (A1, A2) $25 \mu \mathrm{m}$, (B1) $50 \mu \mathrm{m}$, (B2) $10 \mu \mathrm{m}$.

\section{Methods}

\section{Animals and primary cell cultures}

All procedures were approved by the Animal Ethic Committee of Munich University and Edinburgh University. CD1, C57Bl/6, and Mecp2-null mice were killed by cervical dislocation according to the standard protocol. $M e c p 2^{-/ y}$ mice (described in [9]; Jackson Laboratory stock number: 003890) were generated along with wild-type littermates by crossing $M e c p 2^{+/-}$females with wild-type male mice. The generation of mice ectopically expressing LBR in rod cells under the control of the $N r l$ promoter is described in [41]. Retinas of R7E mice [42] were studied at the age of 70 weeks. Retinas from mice with combined deletions of Suv3-9 and Suv4-20 were a kind gift from G. Schotta (University of Munich). Wild-type littermate controls for all genetically modified mice were studied in parallel. Tail fibroblast cell lines from $M e c p 2^{-/ y}$ and Mecp $2^{l o x / y}$ mice are described in [9].

\section{Tissues, fixation, and cryosections}

The retinas of the ICR/CD1 mice were studied on each day between E12 and P28. The retinas of $M e c p 2^{-/ y}$ mice and their WT littermates were studied at the ages of P1, P7, P14, P30, and P53. Retina fixation, embedding in freezing medium, and preparation of cryosections were performed as described previously [38,39]. Briefly, the eyes were enucleated immediately after death; the retinas were dissected and fixed with $4 \%$ formaldehyde in phosphate-buffered saline (PBS) for various times (15 min, $30 \mathrm{~min}, 1 \mathrm{~h}, 3 \mathrm{~h}$, and $24 \mathrm{~h}$ ). After washing in PBS, the samples were infiltrated in $10 \%, 20 \%$, and $30 \%$ sucrose in PBS before freezing in Jung freezing medium. Importantly, the retina samples at different ages, from WT and transgenic mice, and of various fixation times, were arranged in respective order in the same block to assure identification of all retina samples in a section [39]. Retinas from monkey (Macaca fascicularis) and rat (Rattus norvegicus) were post mortem experimental materials from the MPI for Brain Research (Frankfurt, Germany). Other tissue samples from adult $\mathrm{C} 57 \mathrm{Bl} / 6$ mice and rats were fixed with $4 \%$ formaldehyde in PBS for $24 \mathrm{~h}$. For some tissues, the samples from different developmental stages P0, P2, P5, P9, P14, and P28 - were used.

\section{Immunostaining on cryosections}

Immunostaining was performed according to the protocol described in detail by $[38,39]$. This protocol allows quick testing of a wide range of fixation and antigen retrieval times and detection of the range in which the results of staining are robust. Antigen retrieval was crucial for robust MECP2 staining and was performed by heating cryosections in $10 \mathrm{mM}$ sodium citrate buffer at $80^{\circ} \mathrm{C}$. MECP2 detection after $12-24 \mathrm{~h}$ of tissue fixation was most successful after 20-30 min of antigen retrieval. For MECP2 immunostaining, mostly rabbit polyclonal antibodies were used. Specificity of the antibody was checked using fibroblasts derived from $M e c p 2^{-/ y}$ and $M e c p 2^{l o x / y}$ mice (Additional file 1). In some cases, rat monoclonal antibodies were used as well [65]. The antibodies for cell type identification and for recognition of retinal structures are listed in Tables 1 and 3. Antibodies for the detection of histone modifications are listed in Table 2. Secondary antibodies were anti-mouse IgG conjugated to Alexa555 (A31570, Invitrogen, Renfrew, UK) or Alexa488 (A21202, Invitrogen), and anti-rabbit IgG conjugated to DyLight549 (711-505-152, Jackson ImmunoResearch, West Grove, PA, USA) or DyLight 488 (711-485-152, Jackson ImmunoResearch). The nuclei were counterstained with DAPI added to the secondary antibody solution. After staining, the sections were mounted under a coverslip with Vectashield (Vector Laboratories, Inc., Burlingame, CA, USA). 

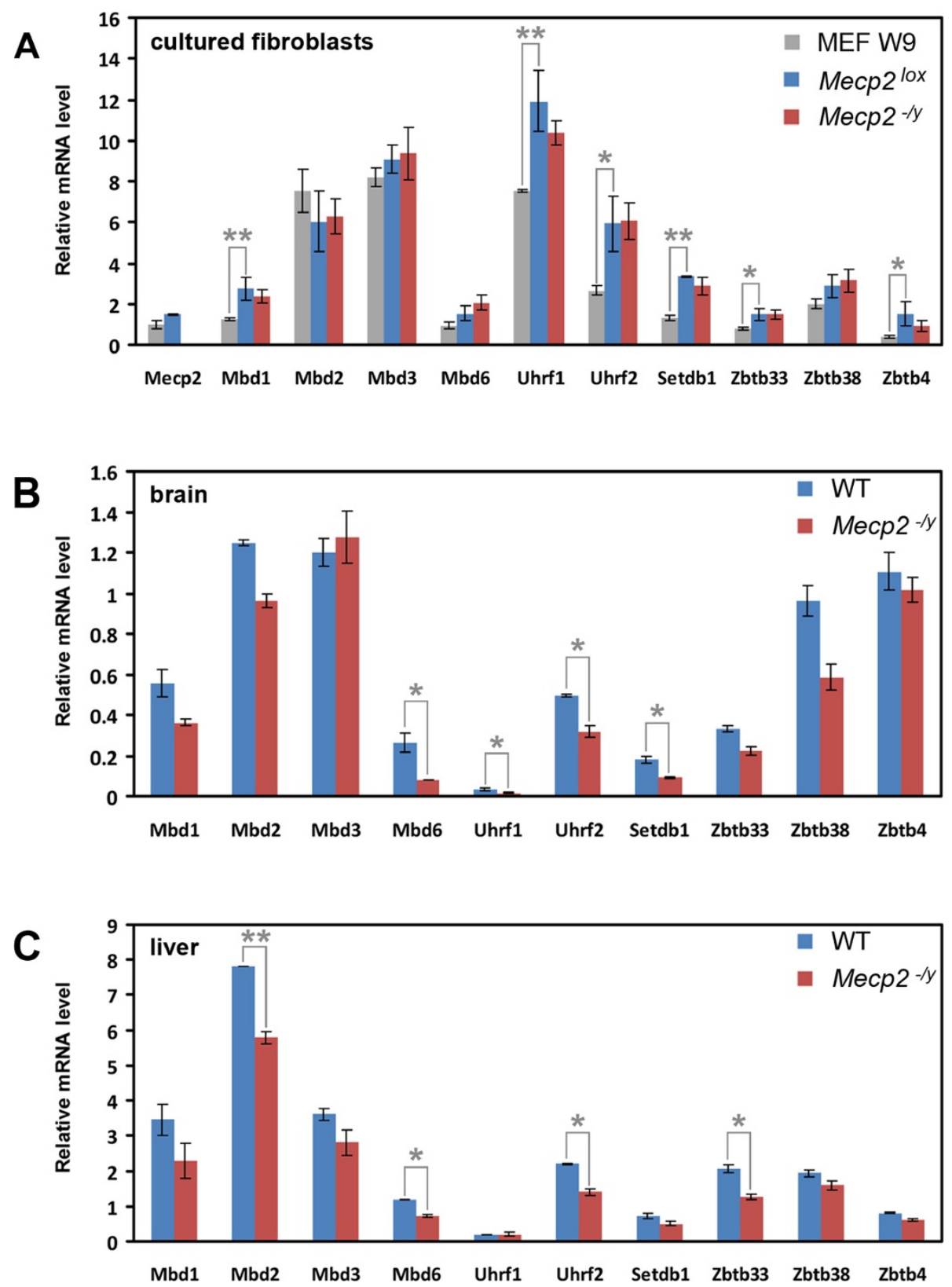

Figure 8 Analysis of expression of MBD proteins in cultured fibroblasts and tissues from $M e c p 2^{-/ y}$ and wild-type mice. (A) Relative transcription level of MBD proteins in wild-type embryonic fibroblasts (MEF W9) and adult fibroblasts established from Mecp2 $2^{-1 y}$ and littermate Mecp $2^{\text {loxy }}$ mice. Values are normalized to the Mecp2 transcript in the embryonic fibroblasts. Note that the mRNA levels in the embryonic and adult fibroblasts differ, whereas no difference in transcription was detected between $M e c p 2^{-l y}$ and Mecp $2^{\text {loxy }}$ genotypes. Relative transcription level of MBD proteins in the brain (B) and liver (C) from Meсp2 $2^{-1 y}$ and littermate Mecp2 $2^{\text {wt }}$ mice. Values are normalized to the Mecp2 transcript in the respective Mecp $2^{\text {wt }}$ tissue. Note that there is no upregulation of MBD protein genes upon deletion of Mecp2. Results of real-time PCR analysis of two (for tissues) and three (for cells) biological replicates are given as mean \pm S.E.M. Statistical difference between values was estimated by $t$ test; statistically significant differences in transcription levels are marked by asterisks $\left({ }^{*}<0.05 ;{ }^{* *}<0.01\right.$ ).

\section{Light microscopy}

Single optical sections or stacks of optical sections were collected using a Leica TCS SP5 confocal microscope (Milton Keynes, UK) equipped with Plan Apo $63 \times / 1.4$ NA oil immersion objective and lasers with excitation lines 405, 488, and $561 \mathrm{~nm}$. Dedicated plugins in the ImageJ program were used to compensate for axial chromatic shift between fluorochromes in confocal stacks, to create RGB stacks/images, and to arrange optical sections into galleries $[66,67]$. 
Table 4 List of primers used for real-time PCR

\begin{tabular}{|c|c|c|}
\hline Gene & Forward & Reverse \\
\hline$M b d 1^{*}$ & GAGCACAGAGAATCGCCTTC & CACACCCCACAGTCCTCTTT \\
\hline$M b d 2^{*}$ & CTGGCAAGATACCTGGGAAA & TTCCGGAGTCTCTGCTTGTT \\
\hline$M b d 3^{*}$ & AGAAGAACCCTGGTGTGTGG & TGTACCAGCTCCTCCTGCTT \\
\hline$M b d 4^{*}$ & ACAGGATGGCTCTGAAATGC & TCTACTTGTGTCCGTGGGATG \\
\hline Mbd5 isoform $1^{* *}$ & GAGGCCATGAGCGAACTG & TCTTCCTCCTCTTGGGTTTG \\
\hline$M b d 6^{* *}$ & CCCGGGGATAGTCAGAAAGT & AGCTGCTCGCGTTGTAGG \\
\hline Meсp2* & CAGGCAAAGCAGAAACATCA & GCAAGGTGGGGTCATCATAC \\
\hline Zbtb33 & ATCATTAGCTCCAGTCCAGACTCA & ATCTGCATCTTCTGTGTCAATGATC \\
\hline Zbtb38* & CATCTTTTGGAGCCATACGATCT & TGACGGTTTCCTGTCTTTTGAC \\
\hline Zbtb4 & CCCTGCCGCTACTGTGAGA & CAGCAGAAGATGCACTGGTACCT \\
\hline Setdb1 & GGCCATTCCTCCCCTACTTC & GGCCAAAGGTGACCGATATG \\
\hline Uhrfi & GGCAGCTGAAGCGGATGA & CCATGCACCGAAGATATTGTCA \\
\hline Uhrf2UHRF2 & CATGGTCGCAGCAATGATG & CACCGCTTCCAGTATACGTGAA \\
\hline Gapdh & CATGGCCTTCCGTGTTCCTA & CTTCACCACCTTCTTGATGTCATC \\
\hline
\end{tabular}

Single asterisk denotes that the sequence was taken from [64]. Double asterisks signify that the sequence was taken from [69].

\section{Chromocenter scoring}

Chromocenters in the rod cells were scored at two age points, P30 and P53. For each age, three mice were used, two $M e c p 2^{-/ y}$ and one $M e c p 2^{+/ y}$ littermate. From each animal $25-\mu$ m-thick cryosections were prepared from the three retina areas: central, mid, and peripheral. To distinguish between individual nuclei in tightly packed rod perikarya, the nuclear envelope of rod cells was stained with anti-lamin B1 antibodies (sc-6217). Between 600 and 800 rod cell nuclei were scored in stacks collected from each retina area. Descriptive statistics was performed using SigmaStat software.

\section{RNA isolation and RT-qPCR}

The tissue samples of Mecp2-null mice were collected in 'RNAlater' (Qiagen, Venlo, Netherlands) and stored at $-20^{\circ} \mathrm{C}$. Isolation of RNA and reverse transcription were carried out as described previously [68]. Primers for RT-qPCR were either designed with the Primer Express software (Applied Biosystems Inc., Foster City, CA, USA) or used as previously published (Table 4). RT-qPCR was performed on the 7500 Fast Real-Time PCR System (Applied Biosystems) at standard reaction conditions using the Power SYBR Green PCR Master Mix (Applied Biosystems). Gene expression levels were normalized to Gapdh and calculated using the comparative CT method ( $\Delta \Delta \mathrm{CT}$ method). Relative quantification of gene expression was performed by the $2^{-\Delta \Delta C T}$ method based on the CT values of both target and reference genes. The results of the real-time PCR analysis of two (tissues) and three (cells) biological replicates are given as mean \pm S.E.M. The statistical difference between the values was estimated by $t$ test using SSPS.

\section{Additional files}

Additional file 1: Immunostaining and Western blot analysis with rabbit anti-MECP2 antibody. Specificity of the rabbit anti-MECP2 antibody and its application for Western blot analysis of MECP2 level in different mouse tissues.

Additional file 2: $M e c p 2^{-1 y}$ and $M e c p 2^{\text {wt }}$ retinas at different developmental stages. Mecp $2^{-y y}$ and Mecp $2^{\text {wt }}$ littermate retinas are not different with respect to the time of layer formation, thickness of nuclear and plexiform layers, and other morphological features.

Additional file 3: Distribution of neurons, synapses, and neurotransmitters in $M e c p 2^{\text {wt }}$ and $M e c p 2^{-\not y}$ retinas. Retinas of $M e c p 2^{-1 y}$ mice show no apparent defects in the distribution of neurons, synapses, and neurotransmitters in comparison to Mecp $2^{\text {ht }}$ littermates.

Additional file 4: Distribution of histone modifications in ganglion and INL cells of $M e c p 2^{\text {wt }}$ and $M e c p 2^{-/ y}$ retinas. Similar distribution of histone modifications characteristic of euchromatin and heterochromatin in $M e c p 2^{-1 y}$ and Mecp2 ${ }^{\text {Wt }}$ mice.

Additional file 5: MECP2 expression in retinal cells from Suv3-9/ Suv4-20 double KO mice. Similar to WT mouse retina, rods of double $\mathrm{KO}$ mice express MECP2 at a very low level, whereas other retinal neurons strongly express MECP2.

Additional file 6: Gene expression analysis of MBD proteins in $M e c p 2^{-/ y}$ and wild-type mice. Relative transcription levels of MBD proteins were determined by RT-qPCR in gut, skeletal muscles and heart of $M e c p 2^{-1 y}$ and Mecp $2^{w t}$ mice.

\section{Abbreviations}

BDNF: Brain-derived neurotrophic factor; GCL: Ganglion cell layer; INL: Inner nuclear layer; MBD: Methyl binding domain; MECP2: Methyl-CpG binding protein 2; ONL: Outer nuclear layer; OPL: Outer plexiform layer; IPL: Plexiform layer; SCA7: Spinocerebellar ataxia type 7; WT: Wild-type.

\section{Competing interests}

The authors declare that they have no competing interests.

\section{Authors' contributions}

CS performed immunostainings, confocal microscopy, RT-qPCR experiments, and data analysis. YF performed immunostainings and confocal microscopy and contributed to manuscript writing. JG collected eye samples and tissues for RT-qPCR. LP supplied antibodies against neural tissues and contributed to manuscript writing. KL supplied anti-MECP2 antibodies and performed Western 
blot analysis. HK supplied antibodies against histone modifications. MCC contributed to the study design and manuscript writing. AB contributed to manuscript writing. HL contributed to manuscript writing. BJ and IS designed and supervised the study; performed immunostainings, confocal microscopy, and data analysis; and wrote the paper. All authors read and approved the final manuscript.

\section{Acknowledgements}

This work was supported by the Deutsche Forschungsgemeinschaft (SO1054/2 to IS, JO903/2 to BJ, SFB 1064/A17 to HL, and CA198/7 to MCC), Grant-in-Aid for Scientific Research on Innovative Areas from the MEXT of Japan (25116005 to HK), and grants from the Rett Syndrome Research Trust and the Wellcome Trust (to $A B$ and JG). The funding bodies had no role in the study design; in the collection, analysis, and interpretation of the data; in the writing of the manuscript; and in the decision to submit the manuscript for publication.

\section{Author details}

'Department of Biology II, Center for Integrated Protein Science Munich (CIPSM), Ludwig Maximilians University Munich, Grosshadernerstrasse 2, 82152 Planegg-Martinsried, Germany. ${ }^{2}$ Wellcome Trust Centre for Cell Biology, University of Edinburgh, EH9 3JR Edinburgh, UK. ${ }^{3}$ Max Planck Institute for Brain Research, Max-von-Laue-Str. 4, Frankfurt am Main 60438, Germany. ${ }^{4}$ Cell Biology and Epigenetics, Department of Biology, Technische Universität Darmstadt, Schnittspahnstr. 10, Darmstadt 64287, Germany. ${ }^{5}$ Graduate School of Frontier Biosciences, Osaka University, 1-3 Yamadaoka, 565-0871 Suita, Osaka, Japan.

Received: 22 June 2014 Accepted: 23 July 2014

Published: 3 August 2014

\section{References}

1. Lewis JD, Meehan RR, Henzel WJ, Maurer-Fogy I, Jeppesen P, Klein F, Bird A: Purification, sequence, and cellular localization of a novel chromosomal protein that binds to methylated DNA. Cell 1992, 69:905-914.

2. Amir RE, Van den Veyver IB, Wan M, Tran CQ, Francke U, Zoghbi HY: Rett syndrome is caused by mutations in X-linked MECP2, encoding methyl-CpG-binding protein 2. Nat Genet 1999, 23:185-188.

3. Chahrour M, Zoghbi HY: The story of Rett syndrome: from clinic to neurobiology. Neuron 2007, 56:422-437.

4. Gonzales ML, LaSalle JM: The role of MeCP2 in brain development and neurodevelopmental disorders. Curr Psychiatry Rep 2010, 12:127-134.

5. Moretti $\mathrm{P}$, Zoghbi HY: MeCP2 dysfunction in Rett syndrome and related disorders. Curr Opin Genet Dev 2006, 16:276-281.

6. Pinto D, Delaby E, Merico D, Barbosa M, Merikangas A, Klei L, Thiruvahindrapuram B, Xu X, Ziman R, Wang Z, Vorstman JA, Thompson A, Regan R, Pilorge M, Pellecchia G, Pagnamenta AT, Oliveira B, Marshall CR, Magalhaes TR, Lowe JK, Howe JL, Griswold AJ, Gilbert J, Duketis E, Dombroski BA, De Jonge MV, Cuccaro M, Crawford EL, Correia CT, Conroy J, et al: Convergence of genes and cellular pathways dysregulated in autism spectrum disorders. Am J Hum Genet 2014, 94:677-694.

7. Bird A: The methyl-CpG-binding protein MeCP2 and neurological disease. Biochem Soc Trans 2008, 36:575-583.

8. Chen RZ, Akbarian S, Tudor M, Jaenisch R: Deficiency of methyl-CpG binding protein-2 in CNS neurons results in a Rett-like phenotype in mice. Nat Genet 2001, 27:327-331.

9. Guy J, Hendrich B, Holmes M, Martin JE, Bird A: A mouse Mecp2-null mutation causes neurological symptoms that mimic Rett syndrome. Nat Genet 2001, 27:322-326.

10. Shahbazian MD, Zoghbi HY: Rett syndrome and MeCP2: linking epigenetics and neuronal function. Am J Hum Genet 2002, 71:1259-1272

11. Cobb S, Guy J, Bird A: Reversibility of functional deficits in experimental models of Rett syndrome. Biochem Soc Trans 2010, 38:498-506.

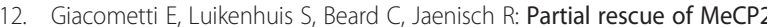
deficiency by postnatal activation of MeCP2. Proc Natl Acad Sci USA 2007, 104:1931-1936.

13. Guy J, Gan J, Selfridge J, Cobb S, Bird A: Reversal of neurological defects in a mouse model of Rett syndrome. Science 2007, 315:1143-1147.

14. Luikenhuis S, Giacometti E, Beard CF, Jaenisch R: Expression of MeCP2 in postmitotic neurons rescues Rett syndrome in mice. Proc Natl Acad Sci USA 2004, 101:6033-6038.
15. Chao HT, Zoghbi HY, Rosenmund C: MeCP2 controls excitatory synaptic strength by regulating glutamatergic synapse number. Neuron 2007, 56:58-65.

16. Smrt RD, Eaves-Egenes J, Barkho BZ, Santistevan NJ, Zhao C, Aimone JB, Gage $\mathrm{FH}$, Zhao X: Mecp2 deficiency leads to delayed maturation and altered gene expression in hippocampal neurons. Neurobiol Dis 2007, 27:77-89.

17. Zhou Z, Hong EJ, Cohen S, Zhao WN, Ho HY, Schmidt L, Chen WG, Lin Y, Savner E, Griffith EC, Hu L, Steen JA, Weitz CJ, Greenberg ME: Brain-specific phosphorylation of $\mathrm{MeCP} 2$ regulates activity-dependent Bdnf transcription, dendritic growth, and spine maturation. Neuron 2006, 52:255-269.

18. Dani VS, Chang Q, Maffei A, Turrigiano GG, Jaenisch R, Nelson SB: Reduced cortical activity due to a shift in the balance between excitation and inhibition in a mouse model of Rett syndrome. Proc Natl Acad Sci U S A 2005, 102:12560-12565.

19. Wood L, Gray NW, Zhou Z, Greenberg ME, Shepherd GM: Synaptic circuit abnormalities of motor-frontal layer 2/3 pyramidal neurons in an RNA interference model of methyl-CpG-binding protein 2 deficiency. J Neurosci 2009, 29:12440-12448.

20. Medrihan L, Tantalaki E, Aramuni G, Sargsyan V, Dudanova I, Missler M Zhang W: Early defects of GABAergic synapses in the brain stem of a MeCP2 mouse model of Rett syndrome. J Neurophysiol 2008, 99:112-121.

21. Ballas N, Lioy DT, Grunseich C, Mandel G: Non-cell autonomous influence of MeCP2-deficient glia on neuronal dendritic morphology. Nat Neurosci 2009, 12:311-317

22. Chen WG, Chang Q, Lin Y, Meissner A, West AE, Griffith EC, Jaenisch R, Greenberg ME: Derepression of BDNF transcription involves calciumdependent phosphorylation of MeCP2. Science 2003, 302:885-889.

23. Tao J, Hu K, Chang Q, Wu H, Sherman NE, Martinowich K, Klose RJ, Schanen C, Jaenisch R, Wang W, Sun YE: Phosphorylation of MeCP2 at Serine 80 regulates its chromatin association and neurological function. Proc Natl Acad Sci USA 2009, 106:4882-4887

24. Tudor M, Akbarian S, Chen RZ, Jaenisch R: Transcriptional profiling of a mouse model for Rett syndrome reveals subtle transcriptional changes in the brain. Proc Natl Acad Sci USA 2002, 99:15536-15541.

25. Maezawa I, Swanberg S, Harvey D, LaSalle JM, Jin LW: Rett syndrome astrocytes are abnormal and spread MeCP2 deficiency through gap junctions. J Neurosci 2009, 29:5051-5061.

26. Maezawa I, Jin LW: Rett syndrome microglia damage dendrites and synapses by the elevated release of glutamate. J Neurosci 2010, 30:5346-5356.

27. Skene PJ, Illingworth RS, Webb S, Kerr AR, James KD, Turner DJ, Andrews R, Bird AP: Neuronal MeCP2 is expressed at near histone-octamer levels and globally alters the chromatin state. Mol Cell 2010, 37:457-468.

28. Joffe B, Leonhardt H, Solovei I: Differentiation and large scale spatial organization of the genome. Curr Opin Genet Dev 2010, 20:562-569.

29. Naumova N, Dekker J: Integrating one-dimensional and threedimensional maps of genomes. J Cell Sci 2010, 123:1979-1988

30. Solovei I, Kreysing M, Lanctot C, Kosem S, Peichl L, Cremer T, Guck J, Joffe B: Nuclear architecture of rod photoreceptor cells adapts to vision in mammalian evolution. Cell 2009, 137:356-368.

31. Brero A, Easwaran HP, Nowak D, Grunewald I, Cremer T, Leonhardt H, Cardoso MC: Methyl CpG-binding proteins induce large-scale chromatin reorganization during terminal differentiation. J Cell Bio/ 2005, 169:733-743.

32. Gilbert N, Thomson I, Boyle S, Allan J, Ramsahoye B, Bickmore WA: DNA methylation affects nuclear organization, histone modifications, and linker histone binding but not chromatin compaction. J Cell Biol 2007, 177:401-411.

33. Matsumura S, Persson LM, Wong L, Wilson AC: The latency-associated nuclear antigen interacts with $\mathrm{MeCP} 2$ and nucleosomes through separate domains. J Virol 2010, 84:2318-2330.

34. Probst AV, Okamoto I, Casanova M, El Marjou F, Le Baccon P, Almouzni G: A strand-specific burst in transcription of pericentric satellites is required for chromocenter formation and early mouse development. Dev Cell 2010, 19:625-638.

35. Singleton MK, Gonzales ML, Leung KN, Yasui DH, Schroeder DI, Dunaway K, LaSalle JM: MeCP2 is required for global heterochromatic and nucleolar changes during activity-dependent neuronal maturation. Neurobiol Dis 2011, 43:190-200.

36. Bertulat B, De Bonis ML, Della Ragione F, Lehmkuhl A, Milden M, Storm C, Jost KL, Scala S, Hendrich B, D'Esposito M, Cardoso MC: MeCP2 dependent heterochromatin reorganization during neural differentiation of a novel Mecp2-deficient embryonic stem cell reporter line. PLoS One 2012, 7:e47848. 
37. Guy J, Cheval H, Selfridge J, Bird A: The role of MeCP2 in the brain. Annu Rev Cell Dev Biol 2011, 27:631-652.

38. Eberhart A, Feodorova Y, Song C, Wanner G, Kiseleva E, Furukawa T, Kimura H, Schotta G, Leonhardt H, Joffe B, Solovei I: Epigenetics of eu- and heterochromatin in inverted and conventional nuclei from mouse retina. Chromosome Res 2013, 21:535-554.

39. Eberhart A, Kimura H, Leonhardt H, Joffe B, Solovei I: Reliable detection of epigenetic histone marks and nuclear proteins in tissue cryosections. Chromosome Res 2012, 20:849-858.

40. Popova EY, Grigoryev SA, Fan Y, Skoultchi Al, Zhang SS, Barnstable CJ: Developmentally regulated linker histone $\mathrm{H} 1 \mathrm{c}$ promotes heterochromatin condensation and mediates structural integrity of rod photoreceptors in mouse retina. J Biol Chem 2013, 288:17895-17907.

41. Solovei I, Wang AS, Thanisch K, Schmidt CS, Krebs S, Zwerger M, Cohen TV, Devys D, Foisner R, Peichl L, Herrmann H, Blum H, Engelkamp D, Stewart CL, Leonhardt $\mathrm{H}$, Joffe B: LBR and lamin A/C sequentially tether peripheral heterochromatin and inversely regulate differentiation. Cell 2013, 152:584-598.

42. Helmlinger D, Hardy S, Abou-Sleymane G, Eberlin A, Bowman AB, Gansmuller A Picaud S, Zoghbi HY, Trottier Y, Tora L, Devys D: Glutamine-expanded ataxin-7 alters TFTC/STAGA recruitment and chromatin structure leading to photoreceptor dysfunction. PLoS Biol 2006, 4:e67.

43. Siegert S, Cabuy E, Scherf BG, Kohler H, Panda S, Le YZ, Fehling HJ, Gaidatzis D, Stadler MB, Roska B: Transcriptional code and disease map for adult retinal cell types. Nat Neurosci 2012, 15:487-495. S481-482.

44. Abou-Sleymane G, Chalmel F, Helmlinger D, Lardenois A, Thibault C, Weber C, Merienne K, Mandel JL, Poch O, Devys D, Trottier Y: Polyglutamine expansion causes neurodegeneration by altering the neuronal differentiation program. Hum Mol Genet 2006, 15:691-703.

45. Kizilyaprak C, Spehner D, Devys D, Schultz P: The linker histone $\mathrm{H} 1 \mathrm{C}$ contributes to the SCA7 nuclear phenotype. Nucleus 2011, 2:444-454.

46. Derecki NC, Cronk JC, Lu Z, Xu E, Abbott SB, Guyenet PG, Kipnis J: Wild-type microglia arrest pathology in a mouse model of Rett syndrome. Nature 2012, 484:105-109.

47. Durand S, Patrizi A, Quast KB, Hachigian L, Pavlyuk R, Saxena A, Carninci P, Hensch TK, Fagiolini M: NMDA receptor regulation prevents regression of visual cortical function in the absence of Mecp2. Neuron 2012, 76:1078-1090

48. Hahn M, Dambacher S, Dulev S, Kuznetsova AY, Eck S, Wörz S, Sadic D, Schulte M, Mallm JP, Maiser A, Debs P, von Melchner H, Leonhardt H, Schermelleh L, Rohr K, Rippe K, Storchova Z, Schotta G: Suv4-20 h2 mediates chromatin compaction and is important for cohesin recruitment to heterochromatin. Genes Dev 2013, 27:859-872.

49. Shahbazian MD, Antalffy B, Armstrong DL, Zoghbi HY: Insight into Rett syndrome: MeCP2 levels display tissue- and cell-specific differences and correlate with neuronal maturation. Hum Mol Genet 2002, 11:115-124.

50. Tochiki KK, Cunningham J, Hunt SP, Geranton SM: The expression of spinal methyl-CpG-binding protein 2: DNA methyltransferases and histone deacetylases is modulated in persistent pain states. Mol Pain 2012, 8:14.

51. Darwanto A, Kitazawa R, Mori K, Kondo T, Kitazawa S: MeCP2 expression and promoter methylation of cyclin D1 gene are associated with cyclin D1 expression in developing rat epididymal duct. Acta Histochem Cytochem 2008, 41:135-142.

52. Agarwal N, Becker A, Jost KL, Haase S, Thakur BK, Brero A, Hardt T, Kudo S, Leonhardt H, Cardoso MC: MeCP2 Rett mutations affect large scale chromatin organization. Hum Mol Genet 2011, 20:4187-4195.

53. Baker SA, Chen L, Wilkins AD, Yu P, Lichtarge O, Zoghbi HY: An AT-hook domain in MeCP2 determines the clinical course of Rett syndrome and related disorders. Cell 2013, 152:984-996.

54. Chahrour M, Jung SY, Shaw C, Zhou X, Wong ST, Qin J, Zoghbi HY: MeCP2, a key contributor to neurological disease, activates and represses transcription. Science 2008, 320:1224-1229.

55. Nan X, Campoy FJ, Bird A: MeCP2 is a transcriptional repressor with abundant binding sites in genomic chromatin. Cell 1997, 88:471-481.

56. Nan $\mathrm{X}, \mathrm{Ng} \mathrm{HH}$, Johnson CA, Laherty CD, Turner BM, Eisenman RN, Bird A Transcriptional repression by the methyl-CpG-binding protein MeCP2 involves a histone deacetylase complex. Nature 1998, 393:386-389.

57. Fisher $L$ : Development of synaptic arrays in the inner plexiform layer of neonatal mouse retina. J Comp Neurol 1979, 187:359-372.

58. Johnson J, Tian N, Caywood MS, Reimer RJ, Edwards RH, Copenhagen DR: Vesicular neurotransmitter transporter expression in developing postnatal rodent retina: GABA and glycine precede glutamate. J Neurosci 2003, 23:518-529.

59. Sherry DM, Wang MM, Bates J, Frishman LJ: Expression of vesicular glutamate transporter 1 in the mouse retina reveals temporal ordering in development of rod vs. cone and ON vs. OFF circuits. J Comp Neurol 2003, 465:480-498.

60. Young RW: Cell differentiation in the retina of the mouse. Anat Rec 1985, 212:199-205.

61. Huntriss J, Hinkins M, Oliver B, Harris SE, Beazley JC, Rutherford AJ, Gosden RG, Lanzendorf SE, Picton HM: Expression of mRNAs for DNA methyltransferases and methyl-CpG-binding proteins in the human female germ line, preimplantation embryos, and embryonic stem cells. Mol Reprod Dev 2004, 67:323-336.

62. Kantor B, Makedonski K, Shemer R, Razin A: Expression and localization of components of the histone deacetylases multiprotein repressory complexes in the mouse preimplantation embryo. Gene Expr Patterns 2003, 3:697-702

63. Lin SL, Chang DC, Lin CH, Ying SY, Leu D, Wu DT: Regulation of somatic cell reprogramming through inducible mir-302 expression. Nucleic Acids Res 2011, 39:1054-1065.

64. Caballero MI, Hansen J, Leaford D, Pollard S, Hendrich BD: The methyl-CpG binding proteins Mecp2, Mbd2 and Kaiso are dispensable for mouse embryogenesis, but play a redundant function in neural differentiation. PLoS One 2009, 4:e4315.

65. Jost KL, Rottach A, Milden M, Bertulat B, Becker A, Wolf $\mathrm{P}$, Sandoval J, Petazzi P, Huertas D, Esteller M, Kremmer E, Leonhardt H, Cardoso MC: Generation and characterization of rat and mouse monoclonal antibodies specific for MeCP2 and their use in X-inactivation studies. PLoS One 2011, 6:e26499.

66. Ronneberger O, Baddeley D, Scheipl F, Verveer PJ, Burkhardt H, Cremer C, Fahrmeir L, Cremer T, Joffe B: Spatial quantitative analysis of fluorescently labeled nuclear structures: problems, methods, pitfalls. Chromosome Res 2008, 16:523-562.

67. Walter J, Joffe B, Bolzer A, Albiez H, Benedetti PA, Muller S, Speicher MR, Cremer T, Cremer M, Solovei I: Towards many colors in FISH on 3D-preserved interphase nuclei. Cytogenet Genome Res 2006, 114:367-378.

68. Szwagierczak A, Bultmann S, Schmidt CS, Spada F, Leonhardt H: Sensitive enzymatic quantification of 5-hydroxymethylcytosine in genomic DNA. Nucleic Acids Res 2010, 38:e181.

69. Laget S, Joulie M, Le Masson F, Sasai N, Christians E, Pradhan S, Roberts RJ Defossez PA: The human proteins MBD5 and MBD6 associate with heterochromatin but they do not bind methylated DNA. PLoS One 2010, 5:e11982.

doi:10.1186/1756-8935-7-17

Cite this article as: Song et al:: DNA methylation reader MECP2: cell type- and differentiation stage-specific protein distribution. Epigenetics \& Chromatin 2014 7:17

\section{Submit your next manuscript to BioMed Central and take full advantage of:}

- Convenient online submission

- Thorough peer review

- No space constraints or color figure charges

- Immediate publication on acceptance

- Inclusion in PubMed, CAS, Scopus and Google Scholar

- Research which is freely available for redistribution 